\title{
Conexões na transformação da experiência do sofrimento psíquico: articulação entre memória e história
}

Cláudia Pellegrini Braga(a)

Braga CP. Connections on transformation of mental suffering experience: relationship between memory and history. Interface (Botucatu). 2017; 21(63):823-32.

The possibility of encountering others in the world is understood,among the diverse models of care, even coming from distinct conceptual bases, as a fundamental experience for people who experience mental suffering. This requires the invention of new practices, something that is being done, and revisiting key-concepts from fields such as psychoanalysis, that need reexamination. A theoretical and critical study about the key concept of memory, understood as constant re-entry of facts and events, was developed; this concept is intertwined with the concept of history, defined as a continuous reconstruction of a process with multiple connections. The analysis was developed in dialogue with philosophy and a literary narrative was presented to give basis to the arguments. The study reflected on the theoretical link between memory, history and mental suffering and reaffirmed that the transformation of mental suffering have links with a specific territory.

Keywords: Psychoanalysis. Philosophy. Interdisciplinary research. Mental health.
Nos modos de atenção aos sujeitos com experiência do sofrimento psíquico, mesmo que de diferentes bases teórico-conceituais, considera-se o encontro com outras pessoas no mundo como primordial para transformação de um processo. Essa posição exige a invenção de novas práticas, o que vem sendo feito, e a releitura de conceitoschave de campos como a psicanálise, que precisam ser reexaminados. Realizou-se um estudo teórico-crítico acerca do conceitochave memória, entendida como incessante reinscrição de fatos e acontecimentos, em uma articulação com o conceito de história, compreendida como reconstrução contínua de um processo com múltiplas conexões. A análise foi desenvolvida em diálogo com a filosofia, e uma narrativa literária foi apresentada para sustentar a argumentação. Refletiu-se sobre a articulação teórica entre memória, história e sofrimento psíquico, e foi assinalado que as possibilidades de transformação se dão, necessariamente, nas conexões com um território.

Palavras-chave: Psicanálise. Filosofia. Pesquisa interdisciplinar. Saúde Mental. (a) Curso de Terapia Ocupacional, Departamento de Fisioterapia, Fonoaudiologia e Terapia Ocupacional, Faculdade de Medicina Universidade de São Paulo (USP). Rua Cipotânea, 51, Cidade Universitária. São Paulo, SP, Brasil. 05360-000. claudia.braga@usp.br 
O cenário das práticas territoriais em saúde mental e dos modos de atenção inovadores junto a sujeitos com experiência do sofrimento psíquico conta, atualmente, com uma pluralidade significativa de proposições, e, mesmo que consideradas a partir de perspectivas distintas, um elemento comum é a afirmação de que o cuidado em liberdade e exercido em um tecido social é primordial. Essas diferentes práticas se baseiam em determinados conjuntos de teorias e conceitos específicos, de modo que alguns são intrínsecos às diretrizes atuais para a construção de novas práticas em saúde mental no campo da saúde pública, sendo expressiva a relevância da perspectiva da desinstitucionalização que afirma os direitos e a cidadania de sujeitos com experiência do sofrimento psíquico, enquanto outros exigem crítica e revisão para sua operacionalização nesse campo, tais como tradicionais conceitos do campo psicanalítico.

Importante notar que, ainda que nos modos de atenção aos sujeitos com experiência do sofrimento psíquico seja possível encontrar distintos campos de referência nas discussões, na dimensão das práticas muitas propostas de atenção tendem a se localizar entre os campos, em um hibridismo. Assim, uma articulação entre diferentes campos ocorre na prática, e porque da prática emerge a necessidade de reinventar a teoria, é preciso, de um ponto de vista crítico, a reflexão e reproposição de conceitoschave tradicionais do campo psicanalítico, em uma releitura que compreende os atravessamentos de distintos campos de conhecimento. Nessa linha, entende-se que a reconsideração conceitual pode contribuir para a compreensão dos modos de atenção, reconhecendo as interfaces que são produzidas no próprio campo das práticas.

Ora, tendo em vista o lugar social e histórico da psicanálise na construção dos modos de atenção em saúde mental, propõe-se retomar um de seus principais conceitos, o de memória, e compreender como podemos recolocá-lo no contemporâneo. De partida, assinala-se que, segundo Derrida, a memória é "a própria essência do psiquismo"1 (p.185), sendo preciso considerar o sofrimento psíquico em uma íntima relação com a memória. Nessa perspectiva, a matriz do sofrimento psíquico estaria relacionada à impossibilidade de conciliação de ser e tempo no interior da memória, com uma "quebra da capacidade de construir uma fala de si que seja a narração do trabalho da memória"2. Não sem razão os modos de atenção aos sujeitos com experiência do sofrimento psíquico, em particular os de orientação ou influência psicanalítica (doravante denominados de clínicas), se transformaram em clínicas das memórias, que compreendem o ato de rememorar como horizonte fundamental de intervenção, sendo o ato de intervenção o de reinscrição da memória em uma história.

Desse modo e nessa chave de leitura, para a investigação teórica desse conceito e de tal clínica de um ponto de vista reflexivo e crítico, é preciso compreender a noção de memória na psicanálise e sua relação com a noção de história. Ainda, com o horizonte afirmado pela prática, de que é imprescindível a dimensão dos encontros com outros nos territórios para a compreensão e transformação da experiência do sofrimento psíquico, e porque é a prática que exige novos conceitos, nesse processo investigativo uma narrativa literária oferecerá a sustentação da discussão. Tal narrativa é apresentada enquanto uma escrita que se relaciona com um devir, no sentido de que o que é apresentado é "um processo, ou seja, uma passagem de vida que atravessa o vivível e o vivido" que busca "instaurar uma zona de vizinhança [...] sob a condição de criar os meios literários para tanto"3 (p. 11). Nessa perspectiva, tais passagens literárias não se constituem "por excesso de realidade ou de imaginação", mas seguem a "via inversa"; do lugar de fabulações, se instalam "descobrindo sob as aparentes pessoas a potência de um impessoal, que de modo algum é uma generalidade, mas uma singularidade no mais alto grau"3 (p. 13). Não se trata, pois, de relato de caso, mas, antes, de uma história que oferece subsídios para uma revisão crítica de conceitos-chave dessas clínicas.

\section{O início de um percurso}

Miranda é um homem adulto com um histórico de experiência do sofrimento psíquico. Na época em que essa narrativa ocorreu, era um usuário de um serviço de saúde mental de base territorial, um Centro de Atenção Psicossocial (CAPS). Não tinha um diagnóstico médico preciso, sendo a ele atribuídas inúmeras identidades nosográficas e oferecidos diferentes psicofármacos como modos de tratamento em outras instituições no decorrer de sua vida. No CAPS, ao me apresentar, Miranda 
olha para mim e afirma: "não há nada aqui". Assim mesmo. Afirmava uma não existência. Pergunto para ele: "como assim?". E ele repete sua afirmação anterior, dizendo não existir. Declarava que frequentava tal serviço porque assim lhe era dito para fazer e acreditava que um dia alguém se daria conta de sua não existência. Naquela época lhe foi sugerida, por um profissional, a escrita de um livro de memórias. Miranda dizia que isso e a medicação eram "bobagens". Mesmo assim, se, por um lado, recusava a medicação, por outro, afirmava que precisava aprender a mexer em um computador para escrever tal livro, afirmando que era algo que iria realizar; o CAPS e os profissionais eram um lugar de referência importante para ele. Passam-se alguns encontros com Miranda e sempre o encontro no serviço. A sua fala continuava a mesma: "para que tomar remédio se não existo?", "não há nada aqui", "preciso aprender a usar o computador".

$\mathrm{Se}$, em um primeiro momento, a fala "não há nada aqui" anuncia um certo tipo de ser sem identidade, é preciso ir adiante em outra camada para compreender que a ideia de identidade, na chave de leitura da psicanálise, é antes de tudo ter a consciência de uma certa continuidade no interior do tempo, com a possibilidade de construção de uma história de si² $^{2}$ Justamente, nessa perspectiva, é a impossibilidade de o sujeito construir uma história de si mesmo, e de se implicar em sua história e em seus processos, que constitui experiências de sofrimento; dito de outro modo, a matriz de sofrimento psíquico é a não conciliação de ser e tempo no interior da memória com uma quebra da capacidade de construir uma fala de si. Assim, a aposta de uma leitura nessa perspectiva clínica, nesse caso, não está em "ele não é" no sentido de ele não existe, mas, antes, em que ele afirma sua não existência na medida em que não pode falar de si; ele experiencia um sofrimento porque não pode falar de si. Ou seja, haveria uma quebra da continuidade do ser.

Tratava-se de um sujeito com uma experiência de corpo disciplinado, que diferentes profissionais que encontrou em sua vida buscavam ordenar sem se ater a um primeiro paradoxo posto: em tal perspectiva, como narrar uma história de si quando está anunciada a quebra da conciliação entre ser e tempo? Ora, submeter a vida a uma narrativa com uma rede de causalidades, como poderia ser a proposta de escrita de uma espécie de autobiografia, é, ao mesmo tempo, tomar posse dela e perdê-la. Assim, possivelmente, a aposta dessa estratégia parecia ser a de que Miranda, ao lembrarse de memórias suas, pudesse criar algum grau de realidade de si no mundo. No entanto, em uma perspectiva psicanalítica, essa perda da vida se dá, de certo modo, por não ser possível considerar o que estaria sob a forma de contingência pela tentativa de reordenar a continuidade histórica em uma suposta rede de causalidades.

Nietzsche (p. 30) descreve um mundo em que os sujeitos são incapazes de esquecer e, por isso, incapazes de narrar o que acontece a não ser pela narrativa linear com relações causais - como se isso permitisse não apenas compreender, mas voltar a desejar; segundo o autor, "em meio a um excesso de história a vida se desmorona e degenera", sendo necessário à própria vida o esquecimento ${ }^{4}$. O que temos a dizer não leva em conta as contingências dos acontecimentos, e, assim, narrar uma história não é necessariamente sinônimo de falar por si mesmo.

Ademais, nesse tipo de proposição opera uma clínica que trata o processo saúde-doença como duas dimensões estáticas (saúde e doença), que necessitariam de intervenção externa para movimentálo. De outro modo, considera-se, aqui, a saúde em um processo e como a possibilidade de o sujeito criar novas normas de vida para si, onde "ser sadio significa não apenas ser normal em uma situação determinada, mas ser, também, normativo, nessa situação e em outras situações eventuais" 5 ; nesse sentido, a saúde é a "possibilidade de ultrapassar a norma que define o normal momentâneo, a possibilidade de tolerar infrações à norma habitual e de instituir normas novas em situações novas" 5 (p. 148). Saúde é, então, poder de revisão e instituição de novas normas para si frente às instabilidades do meio, onde a norma é individual e é reinvindicação do uso de liberdade: as normas são produzidas pela vida para mais vida.

Como afirma Canguilhem, "a vida é, de fato, normativa" (p.86) e a normalidade de alguém se refere à sua própria normatividade ${ }^{5}$. Ora, o limite entre normal e patológico (e, também, entre saúde e doença) se torna assim impreciso se considerarmos diversos sujeitos ao mesmo tempo, já que o "normal não tem a rigidez de um fato coercitivo coletivo, e sim a flexibilidade de uma norma que se transforma em sua relação com condições individuais"; o patológico ou a doença não é, então, a ausência 
completa de normas, mas, sim, é uma "norma inferior, no sentido que não tolera nenhum desvio das condições em que é válida, por ser incapaz de se transformar em outra norma"5 (p.135). Assim, o sujeito doente seria um organismo completamente adaptado e fixo ao meio, que não tem possibilidades de se ajustar conforme as imponderabilidades da vida porque perdeu sua capacidade normativa; ele está doente "em relação a si mesmo" 5 (p.97), sendo a doença uma nova dimensão do viver.

Se viver é confrontar riscos e superá-los ou, como afirma Canguilhem, "estar em boa saúde é poder cair doente e se recuperar" ${ }^{5}$ (p.150), podemos considerar que o sofrimento é esse momento de crise, em que é preciso que o sujeito crie para si uma nova normatividade vital. Não se trata, pois, de ordenar uma suposta normalidade, mas, sim, de possibilitar que ele invente suas próprias normas nessa situação de sofrimento; em uma perspectiva da clínica, possibilitar que crie para si uma narrativa.

Na compreensão exclusiva de uma causalidade orgânica não há histórias, e na tentativa de ordenação de uma série histórica podem surgir histórias lineares, mas, não, acontecimentos, sendo que qualquer possibilidade de transformação continua bloqueada. Justamente, a produção de acontecimentos transformadores é uma questão importante para as clínicas do sofrimento psíquico. Mas, mesmo assim, tantas vezes, percebe-se no discurso de profissionais diversos uma tentativa de ordenar fatos históricos de um sujeito em uma rede de causalidades formada pelo próprio profissional, de modo que, em discussões, os 'casos clínicos' acabam sendo apresentados de modo sequencial: conta-se quantos anos o sujeito tem, ocupação principal, parentescos e depois uma sucessão de fatos de sua história de vida em uma arranjada ordem cronológica, da infância à vida adulta, para assim poder ser apresentado ou formulado um diagnóstico ou uma leitura. Esse discurso está relacionado a um modelo de memória como estoque de experiências e de história como sendo de caráter linear; um modelo em que não há espaço para escuta da história tal como narrada pelo sujeito e da própria vida (e, tampouco, dos processos inconscientes). Este é o risco: a descrição de uma rede de causalidades na narração de uma biografia, como se isso, por si só, fosse explicar o sofrimento do sujeito e possibilitar a constituição de processos terapêuticos.

\section{O entrelaçamento de memória e história na psicanálise}

Dando seguimento a seu projeto terapêutico singular e diante de sua afirmação de que precisava fazer um curso de informática, acompanhei Miranda a um outro CAPS que oferecia o tal curso; tratava-se de uma tentativa de aproximação de um entre-dois. Como o imponderável é constituinte da vida, naquele espaço, ele encontrou Paulo, com quem havia ficado institucionalizado em um hospital psiquiátrico por mais de 10 anos. Também inesperado era o fato de que eu também conhecia Paulo, pois ele participava das atividades de um grupo - um coletivo de criação -, do qual eu também fazia parte. Algo ali se passou para Miranda. Um entrecruzamento entre passado e presente. Um passado que nunca deixou de ser. Miranda foi convidado por Paulo (e não por mim) a participar desse grupo. Apareceu por lá e, continuamente, nos muitos encontros, afirmava a sua não existência - enquanto Paulo insistia em trazer à tona histórias do tempo em que estiveram institucionalizados juntos em um hospital psiquiátrico.

As experiências estão nesse espaço que é da contingência. Por isso - porque a experiência é aberta, não é definida a priori - ao rememorar, o sujeito pode reconstruir seu lugar no mundo. Para Freud ${ }^{6}$, rememorar a experiência significa reelaborá-la a partir das experiências em ato, construindo outra história de si. Mas, nessa perspectiva, quando este processo está interrompido ou, mesmo, quando há uma ruminação incessante de um acontecimento sem sua elaboração, não sendo possível, ao sujeito, criar para si novas normas, tem-se a instauração de uma experiência do sofrimento psíquico.

Da história, é dita ser contínua por se tratar de uma série em processo. Trata-se de um sistema de definições em que, ao acrescentar um outro acontecimento no interior desta série - que é a história -, todos os acontecimentos anteriores se reconfiguram ${ }^{2}$. O acontecimento é entendido, nessa concepção, como aquilo que deixa marcas mimésicas: para ser acontecimento, são necessários esses traços que modificam o universo simbólico. Assim, é por estar inserido nessa série que se pode dizer de um lugar 
subjetivo do sujeito, em que ele produz sentidos para sua existência quando acontecimentos criam marcas nessa cadeia e modificam todos os elementos anteriores, dotando de novos sentidos tais elementos. Esta concepção de história oferece a base para o conceito de rememorar elaborado por Freud $^{6}$, pois, neste campo aberto de possibilidades de significações de toda a série histórica do sujeito, é possível a reorganização simbólica da mesma, reconstruindo e reescrevendo fatos e acontecimentos. Justamente, a clínica de orientação psicanalítica trata disso: repetir, rememorar e reelaborar para que, por meio de um acontecimento, o sujeito possa dotar de novos sentidos a sua história.

Se o quadro teórico da psicanálise trata de compreender o psiquismo e sendo a memória a própria essência do psiquismo, é preciso considerar o sofrimento psíquico em uma íntima relação com a memória. Para a teoria psicanalítica, a memória tem papel essencial no aparelho psíquico e é um ato contínuo de reconstrução do passado a partir do presente. As representações de lembranças não são conteúdos arquivados, mas incessantes ressignificações que dialogam com o presente: a tríade passado-presente-futuro deixa de ser pensada como sucessão e passa a ser pensada como conexão, estando a memória ligada ao tempo. Ainda, para Freud ${ }^{6}$, rememorar a experiência significa reelaborar uma experiência, construindo outra história de si. Destarte, o rememorado nunca é um mero fato, já que o que é rememorado diz respeito às experiências do sujeito. Tendo em vista o próprio conceito de memória, rememorar não é a procura de objetos primeiros intocados e conservados em um estoque de experiências, mas, sim, a tentativa do sujeito em construir para si outras referências no mundo, criando novas associações que possibilitem tipos de agenciamento mais potentes para a produção de vida. Nessa linha, o ato de intervenção analítica é de reinscrição da memória.

Pois é nesse sentido que, na clínica psicanalítica, a associação livre ocupa o lugar privilegiado de vencer as resistências da rememoração pela análise da "superfície psíquica apresentada pelo analisando, utilizando a arte da interpretação essencialmente para reconhecer as resistências que nela surgem e torná-las conscientes" 6 (p. 195). Trata-se de um trabalho de deslocamento do problema para a análise das resistências do sujeito em rememorar; por isso, Freud afirma a necessidade de analisar a superfície psíquica e as resistências, partindo da ideia de que, superadas as resistências, o próprio analisando rememoraria.

O trabalho na psicanálise é, então, compartilhado: o analista analisa as resistências e o sujeito analisado se sente liberado para trazer o material que provocou a situação que se encontra. Com a associação livre, a concepção de rememoração sofre um movimento: rememorar deixa de ser reviver o passado para se tornar um processo de construção. Com a criação da técnica da associação livre, o analisando não tem a tarefa de lembrar-se de algo, mas de, no setting psicanalítico, "conjurar uma fração da vida real", ou seja, repetir ${ }^{6}$ (p. 202).

O conceito de repetição, para Freud ${ }^{6}$, está vinculado à possibilidade de transferência: na cena psicanalítica, o sujeito repete aquilo que não pode acessar conscientemente porque está bloqueado, sendo a transferência um fragmento da repetição; o conceito de repetir tem como sentido atuar, posto que "o analisando não reproduz como lembrança, mas como ato, ele o repete", sem que isso seja consciente ${ }^{6}$ (p. 200). Essa repetição é uma quebra da linearidade temporal, em que passado e presente se contraem em um tempo só, e essa é a condição para a rememoração ser possível. Isso leva à afirmação de que a transferência é fragmento da repetição, sendo a repetição transferência de um passado esquecido. Sendo assim, a repetição transferencial é uma das bases da clínica psicanalítica e consiste na aposta de que as resistências podem ser suspensas para uma posterior modificação da relação do sujeito com seu sofrimento.

Dessa maneira, a associação livre e a repetição transferencial implicam uma forma de acessar um passado esquecido; e se, antes, o sofrimento psíquico deveria ser superado, com o método da associação livre e com a aposta na relação transferencial, o sofrimento passa a ser considerado como parte essencial do viver que, para perder sua força, tem de ser integrado à vida do sujeito; há o que Freud denomina de "reconciliação com o reprimido" 6 (p.203). Tal mudança torna-se possível pela reelaboração ou rememoração da experiência de uma série histórica, com o sentido de trabalhar novamente, de retomar o processo em uma tomada de consciência. 


\section{O entrelaçamento entre história e experiência do sofrimento psíquico: a conexão com o coletivo}

Em uma perspectiva crítica, a história deixa de ser considerada como uma arte narrativa de estocagem de lembranças ${ }^{7}$, para ser entendida como sendo dotada de uma função crítica. Nessa linha, rememorar a experiência significa reelaborar uma experiência, construindo outra história de si, de tal modo que a história é entendida como um tempo que admite rupturas e que visa à transformação de si. O sujeito, ao compreender o tempo do qual faz parte - na tomada de consciência -, pode se transformar.

Porém, quando este processo está interrompido ou, mesmo, quando há uma ruminação incessante de um acontecimento sem sua elaboração - nos termos de Nietzsche, o não esquecimento -, não sendo possível, ao sujeito, criar para si novas normas, pode ocorrer a instauração de um sofrimento psíquico: "há um grau de insônia, de ruminação, de sentido histórico, no qual o vivente se degrada e por fim sucumbe, seja ele um homem, um povo ou uma cultura" 4 (p. 10). A ideia de memória patológica encontra-se nesse cenário e está, necessariamente, relacionada com a dimensão histórica do ser.

Assim, a capacidade de falar por si e de elaborar uma história, construindo normatividades singulares, é o que possibilitaria uma situação de saúde mental. Já estar estancado em um dado acontecimento, sendo o sujeito incapaz de esquecer, é a ideia da história como adoecimento, no sentido de que se articula a uma impossibilidade de o sujeito inventar outras formas de ser e estar no mundo frente a um dado acontecimento. Se, como afirma Canguilhem ${ }^{5}$, esse processo se dá em relação a um meio e se, como afirma Freud de modo geral em sua obra, um sujeito necessariamente precisa do outro para viver, é preciso afirmar que as histórias de uma sociedade e de um sujeito particular, com seus sofrimentos, estão profundamente interligadas: é na conexão com outros que um sujeito faz parte da história e pode reconstruir a história de si.

Como afirmado, na transformação de uma história de si, com a compreensão do tempo em relação ao qual o sujeito faz parte, é possível a tomada de consciência. Isso se coloca porque, com o advento dessa concepção de história, a noção de consciência se altera. A depender da perspectiva, a ideia de consciência está vinculada a um ato de operações do pensar voltados para si mesmo - como evidenciado na segunda meditação cartesiana. Em outro entendimento, ter consciência significa habitar um tempo elástico, e não mais instantâneo, onde passado, presente e futuro se entrelaçam. Tal como Lacan afirma, "a história não é o passado. A história é o passado na medida em que é historiado no presente - historiado no presente porque foi vivido no passado"8 (p.21). Nesse sentido, a história pode impedir o "isolamento da consciência na figura do indivíduo atomizado, isto ao mostrar como a essência da consciência encontra-se na reconciliação de seu ser com um tempo social rememorado" 2 .

O sujeito com seu sofrimento, necessariamente, faz parte de um coletivo que perdura no tempo. A história é, nesse cenário, ato contínuo de reelaboração porque é um processo de compreensão da experiência social e subjetiva dos sujeitos; e é quando a história traz a instabilidade dos conflitos passados, que os sentidos das tensões das experiências podem ser elaborados.

Vale notar que o termo que defende por exclusão a consciência histórica é a consciência alienada, que não tem acesso à totalidade da experiência social. A consciência alienada é aquela que se encontra em um processo de reificação de algo porque só enxerga este algo, um fato específico; por não haver a compreensão histórica, não é possível a reconstrução de uma realidade. Justamente, retomando Nietzsche ${ }^{4}$, "é impossível viver, em geral, sem esquecimento", e aquele que não esquece adoece; assim, como processo singular inserido em uma experiência social, é preciso que o sujeito:

saiba mesmo tão bem esquecer no tempo certo quando lembrar no tempo certo; que se pressinta com um poderoso instinto quando é necessário sentir de modo histórico, quando de modo a-histórico. Esta é justamente a sentença que o leitor está convidado a considerar: o histórico e o a-histórico são na mesma medida necessários para a saúde de um indivíduo, um povo e uma cultura ${ }^{4}$. (p.11) 
Assim, as histórias de uma sociedade e de um sujeito particular estão profundamente interligadas: é na conexão com outros que um sujeito faz parte da história e pode reconstruir a história de si; a possibilidade de saúde tal como descrita por Canguilhem ${ }^{5}$ está inscrita nesse cenário, já que poder regular-se em relação a um meio, considerando o histórico e o a-histórico, é sinal de saúde.

Se, em uma perspectiva, a história é entendida como simples descrição dos fatos em uma visão de testemunho, e o ato de rememorar é compreendido como estocagem; em outra leitura, pode-se compreender a história como ato de se apropriar conscientemente de nossas ações, refletindo sobre as mesmas. É, por meio da história, que ser e tempo se reconciliam no interior da memória², sendo a memória esse espaço de conexão entre ser e tempo, e estando essa definição articulada ao que podemos entender por sujeito - a ponto de que um sujeito desprovido de memória (e história) é um alguém em estado de alienação.

A aposta da escrita de um livro de memórias poderia ser a de que, supostamente, ao preencher o sujeito de memórias, ele seria retirado de um estado de alienação. No entanto, é o que essa proposição provoca de circulação no território e o reencontro com Paulo, que insistia em narrar a sua verdade histórica, mais com um caráter afetivo do que de conteúdo, e que já era, em si, uma reconstrução, que provocou deslocamentos; um reencontro nos territórios de vida.

\section{O vínculo entre história e ser no interior do tempo}

Miranda fazia parte do coletivo de criação. Certo dia, fomos às ruas fotografar cenas urbanas para compor um vídeo. Dias depois, em outro encontro, Miranda olha para as fotografias já reveladas e espalhadas no chão e, nelas, olha para uma imagem de si mesmo, se reconhecendo. Assustado, questiona quem é aquele - e as pessoas lhe dizem que aquele era ele mesmo. Fica calado durante um longo período. Algum tempo depois, Miranda pede ao grupo um momento para falar: desenha uma cruz gamada - uma suástica invertida - e começa uma longa explanação sobre aquele símbolo, relacionando sua origem ao significado de mudança e comparando-o ao símbolo nazista. Os demais presentes apenas escutam e o olham sem entender o que era tudo aquilo. Subitamente, Miranda se levanta e vai embora.

Naquele momento ninguém entendeu o que estava acontecendo com Miranda. Ele foi embora muito rapidamente. Diante do presente - afetos, pessoas, fotos -, ele parece ter organizado algo de um modo singular; pode ser que tenha havido uma articulação entre memória e história naquele momento. Em geral, o passado é campo de significação do próprio presente e está em constante movimento e reordenação; para Miranda, isso parecia estar paralisado, mas, naquele momento, algo foi deslocado em razão de um acontecimento. É a memória, no sentido vivo, e não no sentido de estoque de lembranças, que impulsiona a dinâmica de um processo bloqueado. Memória que está articulada à história, e história que é de mais de um: é de um coletivo. Aquele que se dizia não-ser parecia ter reconstruído uma história de si. O que restava saber era qual seria a possibilidade de Miranda de frente a um acontecimento reconstruir outra norma.

Na semana seguinte, o encontro no CAPS. Ele está diferente e solicita conversar. Começa falando que saiu abruptamente daquele último encontro porque não entendeu o que estava fazendo ao falar sobre a suástica invertida. E narra que, ao entrar no ônibus, aquilo o estava incomodando profundamente, pois não conseguia encontrar uma explicação do porque havia falado aquilo para o grupo, não encontrava sentido no que havia feito. Então, em suas palavras, algo "destravou", e ele afirmou: "eu percebi: eu falei aquilo porque sou louco! Eu sou completamente louco!". Diante da minha surpresa, ele continua: "E aí eu entendi que se eu sou louco, eu sou alguma coisa...". Olhou para mim e, enquanto tocava em seu próprio ombro, falava: "olha só, eu tenho corpo, faz barulho, eu estou aqui".

Uma dinâmica afetiva ganha estabilidade e novos horizontes. Vale destacar que não se trata aqui de buscar uma categoria nosográfica de qualquer ordem para esse sujeito. Mas, antes, assinalar que a possibilidade de transformação de uma experiência do sofrimento psíquico está relacionada com as conexões que podem ser produzidas no encontro com outros, nos territórios de vida. 
A clínica produz tentativas de ordenadores, mas a história apresentada pelo sujeito traz uma multiplicidade e tal imprevisibilidade que não pode ser contida por quaisquer clínicas. O sujeito está inserido em um campo de experiências compartilhadas, tomando parte em experiências sociais com outros. Assim, é preciso deixar a multiplicidade das relações, dos contextos e da vida invadir os modos de atenção e o espaço dos serviços, criando raízes com o mundo. Nesse sentido, a aposta necessária para a produção de saúde é de ultrapassar quaisquer paredes, seja de um serviço, seja de um enquadre teórico, e de explorar as potências das relações em um território social, abrindo para novos sentidos e redes de significações e compreensões.

Como exemplo, vale a leitura da proposta de compreensão de Deleuze e Guattari ${ }^{9}$ acerca do caso O Homem dos Lobos $^{10}$. Deleuze e Guattari ${ }^{9}$ (p.54), ressignificando esse caso, afirmam que o problema é que nenhum analista foi capaz de reconstruir o significado da ideia de lobo, ninguém explorou outras reverberações do significado, fazendo sempre um "retorno à unidade". Ao contrário, era preciso abrir os sentidos, vincular a história trazida a outras dimensões, agenciar a rede de significações: "o lobo é a matilha, quer dizer, a multiplicidade apreendida como tal em um instante" 9 (p.58); assim, mais do que compreender, é necessário explorar as ambivalências e intensidades das relações. Para tanto, para Deleuze, é preciso explorar os agenciamentos estabelecidos pelo desejo em um coletivo. Nesse caso, indagar: "onde passa meu desejo na matilha? Qual é minha posição na matilha? Sou exterior à matilha?"11.

Ora, acerca do desejo, Deleuze afirma que esse "constrói agenciamentos, se estabelece em agenciamentos, põe sempre em jogo vários fatores", enquanto "a psicanálise nos reduz sempre a um único fator, e sempre o mesmo, ora o pai, ora a mãe, ora não sei o que, ora o falo (...), ignora tudo o que é múltiplo"11. Deleuze, para exemplificar tal questão, relata que, certa vez, Jung contou a Freud que "sonhou com um ossuário", e que Freud não compreendeu isso, afirmando que "se sonhou com um osso, é a morte de alguém, quer dizer a morte de alguém"; mas, para Deleuze, "Freud não compreende. Não vê a diferença entre um ossuário e um osso, ou seja, um ossuário são centenas de ossos, são mil, dez mil ossos", concluindo que isso, o ossuário, "é uma multiplicidade, é um agenciamento"11.

Assim, na perspectiva de Deleuze, as pessoas "desejam sempre um conjunto"11. Justamente, é nesse sentido que se pode afirmar que o delírio, que está "ligado ao desejo", estabelece agenciamentos em um coletivo, de modo que "não se delira sobre seu pai e sua mãe, delira-se sobre algo bem diferente, é aí que está o segredo do delírio, delira-se sobre o mundo inteiro, delira-se sobre a história, a geografia, as tribos, os desertos, os povos"11. Nesse episódio da narrativa, portanto, não se trata de fazer qualquer tipo de interpretação, mas de assinalar a necessidade de procurar outros agenciamentos, complexificando a compreensão dos contextos e das múltiplas relações; em síntese, "o delírio é geográfico-político"11.

Nesse sentido, é preciso afirmar que o sujeito está inserido em um campo de experiências compartilhadas, tomando parte em experiências sociais com outros, em camadas temporais que não se esgotam em uma individualidade. O processo da clínica não se ocupa apenas das experiências particulares, mas, também, dos impactos de experiências transindividuais, dos encontros. Nessa narrativa literária, em uma leitura a partir da perspectiva da clínica, a reconciliação entre ser e tempo no interior da memória se deu, duplamente e concomitantemente, por um processo singular de criação de outras normatividades diante daquele meio e pela vivência de experiências compartilhadas. A rememoração enquanto síntese do tempo em uma unidade implicou justamente nisso: Miranda pôde apresentar, para si mesmo, outra narrativa possível que significasse aquela experiência a partir do encontro com outros no mundo.

Assim, o sofrimento psíquico vivenciado por um sujeito deixa de ter um caráter particular, para compor com o social e no social, sendo possíveis as transformações no encontro em um solo comum: Miranda, com os outros, se descobre louco. Vale destacar que não há um caráter determinista neste acontecimento, e não cabe aqui traçar uma relação causal do tipo: reencontro com antigo colega retorno para experiências passadas - ver-se no presente - transformação do sofrimento. Novamente, não se trata de uma relação determinista, mas, ao contrário, de afirmar a necessidade de abertura 
para uma rede de possíveis significações que escapam de uma única unidade narrativa; afirmar a importância das conexões com o território, em uma rede de relações.

\section{Um parêntese}

Afirma-se, aqui, que a possibilidade de rememoração está para além de uma relação dual. Ora, na clínica de orientação psicanalítica, a análise é uma experiência de reelaboração e só o sujeito pode operar esse processo. O que se defende aqui, é que, mesmo nesse cenário, as condições de enunciação da questão se dão para além de um encontro dual analista-analisando, dado que o processo de constituição psíquica ocorre em relações interpessoais. A intervenção dessas clínicas pode ocupar esse lugar de, em uma fala performativa, fornecer condições para que o sujeito possa organizar o sofrimento psíquico em uma história, organizando a história de seu desejo. Mas, esse processo de rememoração está profundamente ligado à história, que está inscrita em campo maior do que a vida particular do sujeito, que é a história de um coletivo. Assim, é preciso reconhecer a alteridade e a multiplicidade como constituintes do próprio psiquismo dos sujeitos, e valorar a própria repetição em seu sentido positivo, dando lugar, não para aquilo que se encadeia e que produz causalidade, mas para os esquecimentos e para o que é descontínuo e da contingência, que é de onde podem surgir acontecimentos.

\section{Traços de uma conclusão}

De modo geral, como foi assinalado, na dimensão das novas práticas em saúde mental, compreende-se que, para a transformação de um processo, é necessário investimento em múltiplas conexões entre os sujeitos e um certo tecido social, abrangendo os territórios e os coletivos, com o cuidado exercido em liberdade. Na perspectiva da desinstitucionalização, afirmam-se, ainda, os direitos e a cidadania dos sujeitos com experiência do sofrimento psíquico, assinalando a necessidade de transformação das relações produzidas em um contexto social. Buscando avançar na compreensão de conceitos do campo psicanalítico, nesse estudo, foi feita uma investigação, em uma perspectiva crítica, que procurou desenvolver uma articulação teórica entre memória e história na interface com as discussões da filosofia, enfatizando a importância das conexões entre sujeitos e coletivos nos territórios. Assim, no âmbito das clínicas, é preciso investir em modos de atenção aos sujeitos com experiência do sofrimento psíquico que reconheçam que é apenas nos territórios reais de vida e em um contexto de múltiplas conexões com outros que é possível produzir transformações de si e de um tecido social.

\section{Referências}

1. Derrida J. A escritura e a diferença. São Paulo: Perspectiva; 1995.

2. Safatle V. Epistemologia das ciências humanas. FFLH/USP [Internet]; 2013 [citado 12 Maio 2016]. Disponível em: http://filosofia.fflch.usp.br/es/node/1219.

3. Deleuze G. Crítica e clínica. Rio de Janeiro: Editora 34; 2011.

4. Nietzsche F. Segunda consideração intempestiva: as vantagens e desvantagens da história para vida. Rio de Janeiro: Relume-Dumará; 2003. 
5. Canguilhem G. O normal e o patológico. Rio de Janeiro: Forense Universitária; 2010.

6. Freud S. Observações psicanalíticas sobre um caso de paranoia relatado em autobiografia: ("O caso Schreber"): artigos sobre técnicas e outros textos. São Paulo: Companhia das Letras; 2010.

7. Derrida J. Mal de arquivo: uma impressão freudiana. Rio de Janeiro: Relume-Dumará; 2001.

8. Lacan J. O seminário: os escritos técnicos de Freud (livro 1). Rio de Janeiro: Jorge Zahar; 1986.

9. Deleuze G, Guatarri F. Mil platôs. Capitalismo e Esquizofrenia. Rio de Janeiro: Editora 34; 1995.

10. Freud S. História de uma neurose infantil ("O homem dos lobos"): além do princípio do prazer e outros textos. São Paulo: Companhia da Letras; 2010.

11. Deleuze G, Parnet C. L'abécédaire de Gilles Deleuze [vídeo]. Paris: Éditions Montparnasse; 1996.

Braga CP. Conexiones en la transformación de la experiencia del sufrimiento síquico: articulación entre memoria e historia. Interface (Botucatu). 2017; 21(63):823-32.

En los modos de atención a los sujetos con experiencia de sufrimiento síquico, aunque de diferentes bases teórico-conceptuales, se considera el encuentro con otras personas en el mundo como primordial para la transformación de un proceso. Esa posición exige la invención de nuevas prácticas, lo que se ha realizado, y la relectura de conceptos-clave de campos como el psicoanálisis que tienen que reexaminarse. De esa forma, se realizó un estudio teórico-crítico sobre el concepto-clave memoria, entendida como una incesante re-inscripción de hechos y acontecimientos en una articulación con el concepto de la historia, entendida como reconstrucción continua de un proceso con múltiples conexiones. El análisis se desarrolló en diálogo con la filosofía y se presentó una narrativa literaria para sostener la argumentación. Se reflexionó sobre la articulación teórica entre memoria, historia y sufrimiento síquico y se señaló que las posibilidades de transformación suceden, necesariamente, en las conexiones con un territorio.

Palabras clave: Psicoanálisis. Filosofía. Investigación interdisciplinar. Salud mental. 